Acta Crystallographica Section F

Structural Biology

and Crystallization

Communications

ISSN 1744-3091

Scott Cameron, Karen McLuskey, Rachel Chamberlayne, Irene Hallyburton and William N. Hunter*

Division of Biological Chemistry and Molecular Microbiology, School of Life Sciences, University of Dundee, Dundee DD1 5EH, Scotland

Correspondence e-mail:

w.n.hunter@dundee.ac.uk

Received 31 March 2005

Accepted 19 April 2005

Online 28 April 2005

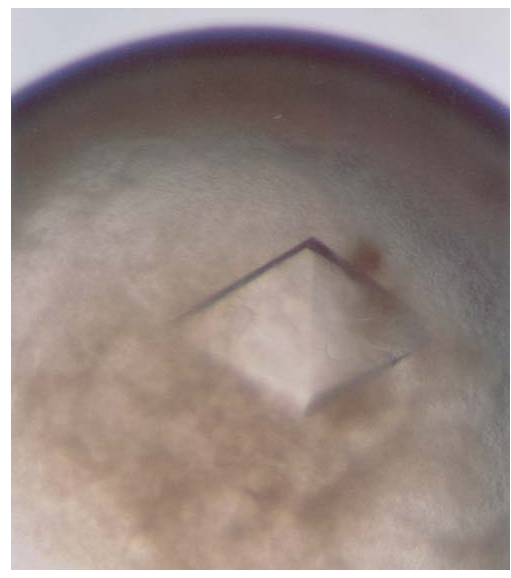

(C) 2005 International Union of Crystallography All rights reserved

\section{Initiating a crystallographic analysis of recombinant (S)-2-hydroxypropylphosphonic acid epoxidase from Streptomyces wedmorensis}

The oxirane $(1 R, 2 S)$-1,2-epoxypropylphosphonic acid (fosfomycin) is a natural product antibiotic produced in Streptomyces wedmorensis by the metal-iondependent $(S)$-2-hydroxypropylphosphonic acid epoxidase. This epoxidase is highly unusual since it has no requirement for a haem prosthetic group. The gene encoding the enzyme, fom 4 , has been cloned and a highly efficient recombinant source of the enzyme established. Two different crystal forms, tetragonal and hexagonal, have been obtained. The hexagonal form displays symmetry consistent with space group $P 6_{1 / 5} 22$ and unit-cell parameters $a=86.44, c=221.56 \AA, \gamma=120^{\circ}$. The Matthews coefficient, $V_{\mathrm{M}}$, of $2.7 \AA^{3} \mathrm{Da}^{-1}$ corresponds to two subunits, each of approximate weight $21.4 \mathrm{kDa}$, in the asymmetric unit with $55 \%$ solvent content. These crystals diffract to high resolution and experimental phases are being sought to determine the structure.

\section{Introduction}

Fosfomycin, $(1 R, 2 S)$-1,2-epoxypropylphosphonic acid, is a broadspectrum antimicrobial produced by Streptomyces wedmorensis and Pseudomonas syringae (Hendlin et al., 1969; Shoji et al., 1986). The antibiotic has mainly been used in the treatment of urinary-tract infections, where it exhibits low toxicity and few side effects (Patel et al., 1997). More recently, efficacy against $P$. aeruginosa in cystic fibrosis patients has been demonstrated (Mirakhur et al., 2003). Fosfomycin inhibits UDP-GlcNAc-3-O-enolpyruvyltransferase (MurA), an enzyme essential for bacterial cell-wall peptidoglycan synthesis (El Zoeiby et al., 2003). Specifically, the drug alkylates an active-site cysteine in MurA (Kim et al., 1996). One interest in the enzymes involved in the production of this antimicrobial drug is the application of protein-engineering methods to assist in the development of new antimicrobials based upon the fosfomycin structure.

Fosfomycin is a member of a growing family of natural products containing $\mathrm{C}-\mathrm{P}$ bonds, such as the herbicides phosphinothricin and bialaphos, which are derived from phosphoenolpyruvate (PEP; Seto \& Kuzuyama, 1999; Woschek et al., 2002). An intermolecular rearrangement of PEP results in the formation of phosphonopyruvic acid and decarboxylation followed by methylation gives $(S)$-2hydroxypropylphosphonic acid (HPP), the precursor to fosfomycin. The early steps of this pathway are well established; however, much less is understood about the remaining steps, especially the unusual mechanism of the oxiranyl ring formation (Liu et al., 2003).This final step in the pathway is the epoxidation of HPP to produce fosfomycin, a reaction that is catalysed by the enzyme HPP epoxidase (Zhao et al., 2002). HPP epoxidase is a $21.4 \mathrm{kDa}$ protein consisting of 198 amino acids, reported to be iron(II)-dependent and to form a homotetramer (Liu et al., 2003).

Here, we describe the cloning of the $S$. wedmorensis fom 4 gene, which encodes HPP epoxidase, the construction of a highly efficient protein-expression system and purification of the recombinant enzyme along with crystallization and preliminary diffraction experiments. 


\section{Methods and results}

\subsection{Preparation of recombinant HPP epoxidase}

Genomic DNA was extracted from $S$. wedmorensis (ATCC 21239) using cetyl trimethylammonium bromide, the so-called C-TAB method (Wilson, 1994). This provided the template for PCR with the following primers designed to amplify the fom 4 open reading frame with NdeI and BamHI restriction sites (bold), respectively: 5'-CATATG-AGC-AAC-ACC-AAG-ACA-GGA-G-3', 5'-GGA-TCC-TCAGAA-GTT-GAC-GGC-TTC-3'. The resultant single product was cloned into the pCR-BluntII-TOPO vector using the Zero Blunt TOPO PCR cloning kit (Invitrogen). Positive clones were sequenced to confirm the integrity of the product and then, following excision, the fom 4 gene was ligated into the expression vector pET-15b (Novagen). This ultimately produces a protein carrying an N-terminal hexahistidine tag (His-tag), which permits the use of metal-chelating chromatography for purification. The recombinant plasmid was then heat-shock transformed into Escherichia coli XL-1 blue cells (Invitrogen) for DNA amplification before being transformed into $E$. coli BL21 (DE3) for protein expression. The new plasmid was selected on Luria-Bertani agar plates containing $50 \mu \mathrm{g} \mathrm{ml}^{-1}$ carbenicillin (LB/carbenicillin). Bacteria were cultured in $11 \mathrm{LB} /$ carbenicillin at $310 \mathrm{~K}$ to an $\mathrm{OD}_{600}$ of $0.6-0.7$ and then induced with $0.3 \mathrm{~m} M$ isopropyl- $\beta$-D-thiogalactopyranoside. The culture was then left overnight at room temperature with constant shaking. Cells were harvested by centrifugation $(2500 \mathrm{~g}, 20 \mathrm{~min}, 277 \mathrm{~K})$ and resuspended in $50 \mathrm{~m} M$ Tris- $\mathrm{HCl} \mathrm{pH} 7.9,250 \mathrm{mM} \mathrm{NaCl}$ before being broken open by passage through a One-Shot cell disruptor (Constant Systems) and

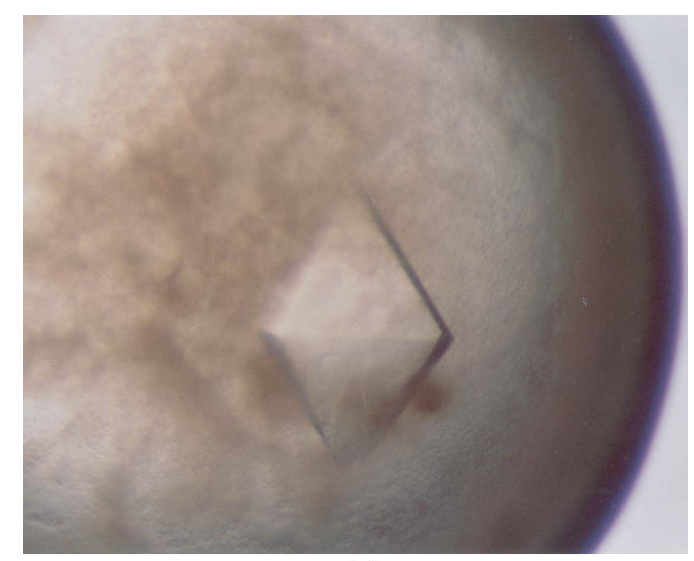

(a)

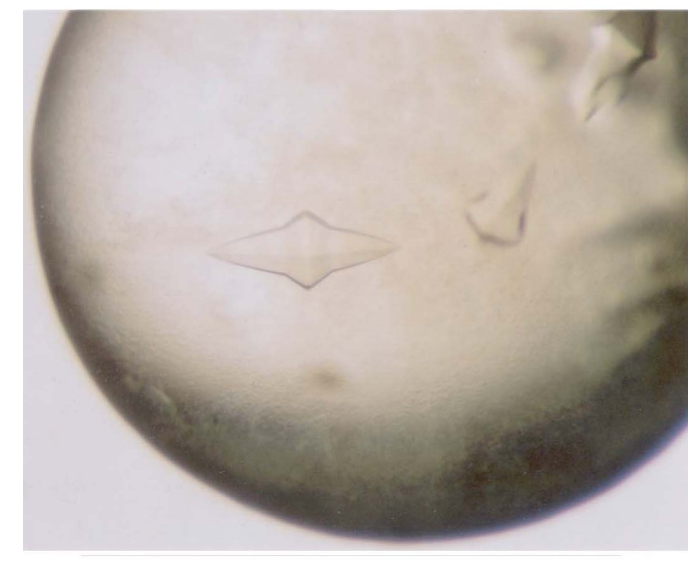

(b)

Figure 1

(a) Form I HPP epoxidase crystals, (b) a form II HPP epoxidase crystal. the insoluble cell debris separated by centrifugation (38 000g, $20 \mathrm{~min}$, $277 \mathrm{~K})$. The cell extract was then filtered and applied onto a $5 \mathrm{ml}$ metal-chelating column (Hi-Trap; Pharmacia) charged with $\mathrm{Ni}^{2+}$. The column was washed with $50 \mathrm{~m} M$ Tris- $\mathrm{HCl} \mathrm{pH} 7.9,250 \mathrm{mM} \mathrm{NaCl}$ and the His-tagged protein was eluted with a $0-600 \mathrm{~m} M$ imidazole gradient in the same buffer. The eluted protein was incubated at room temperature with 50 units of thrombin (Pharmacia) for $3 \mathrm{~h}$ at $293 \mathrm{~K}$ to remove the His tag. The protein was then dialysed overnight at $277 \mathrm{~K}$ into $50 \mathrm{mM}$ Tris- $\mathrm{HCl} \mathrm{pH} 7.9$ and separated from the thrombin and cleaved $\mathrm{N}$-terminal peptide by anion-exchange chromatography using a Porus HQ strong anion-exchange column (Applied Biosystems). Pooled fractions containing HPP epoxidase were dialysed into $20 \mathrm{~m} M$ Tris- $\mathrm{HCl} \mathrm{pH} 7.9,50 \mathrm{~m} M \mathrm{NaCl}$ overnight at $277 \mathrm{~K}$ and concentrated to $\sim 30 \mathrm{mg} \mathrm{ml}^{-1}$. The purity of the enzyme sample was determined using both sodium dodecyl sulfate-polyacrylamide gel electrophoresis and matrix-assisted laser desorption ionization-time-of-flight mass spectrometry (Voyager DE STR, Applied Biosystems) prior to crystallization experiments. The yield of purified protein was approximately $60 \mathrm{mg}$ per litre of cell culture.

\subsection{Analytical ultracentrifugation}

The quaternary structure of the protein was reported to be a tetramer based on molecular-sieve chromatography (Liu et al., 2003). To confirm this result, HPP epoxidase was analysed by analytical ultracentrifugation. Samples were prepared in $20 \mathrm{mM}$ Tris- $\mathrm{HCl} \mathrm{pH}$ $7.9,50 \mathrm{mM} \mathrm{NaCl}$ at concentrations that gave $\mathrm{OD}_{280}$ readings of 0.5 , 1.0 and $2.0\left(0.4,0.8\right.$ and $1.7 \mathrm{mg} \mathrm{ml}^{-1}$, respectively) in a $1.2 \mathrm{~cm}$ pathlength cell. Sedimentation-equilibrium determinations were carried out using an Optima XL-1 analytical ultracentrifuge (Beckman Coulter) with absorbance optics. The sedimentation-velocity experiments were run at $35000 \mathrm{rev} \min ^{-1}$ at $293 \mathrm{~K}$ and the data were analysed with the program SEDFIT (Schuck, 2000). Two sedimentation coefficients of 3.2 and 5.1, consistent with molecular weights of approximately 40 and $80 \mathrm{kDa}$, were observed at each concentration. The weight ratio of the $80 \mathrm{kDa}$ peak to the $40 \mathrm{kDa}$ peak was $\sim 20: 1$ for the two lower protein concentrations and $\sim 70: 1$ for the highest, confirming that the major and most stable species of HPP epoxidase is likely to be a homotetramer.

\subsection{Crystallization}

Initial crystallization experiments were preformed with commercially available screens. Screening was carried out in 96-well trays using sitting drops containing $1 \mu \mathrm{l}$ protein plus $1 \mu \mathrm{l}$ of the reservoir set up for vapour diffusion against $500 \mu \mathrm{l}$ reservoir at $293 \mathrm{~K}$. Small crystals appeared within a couple of days using $2.0 \mathrm{M}$ ammonium sulfate, $100 \mathrm{~m} M$ Tris- $\mathrm{HCl} \mathrm{pH} 8.5$ as the reservoir. This condition was optimized using $2 \mu \mathrm{l}$ purified HPP epoxidase plus $2 \mu \mathrm{l}$ reservoir comprising $2.1 \mathrm{M}\left(\mathrm{NH}_{4}\right)_{2} \mathrm{SO}_{4}$ in $100 \mathrm{mM}$ Tris- $\mathrm{HCl} \mathrm{pH}$ 7.5. These conditions produced large $(0.5 \times 0.4 \times 0.4 \mathrm{~mm})$ tetragonal crystals (Fig. 1a), designated crystal form I. Although of good appearance and size, these crystals unfortunately displayed a high mosaic spread and diffracted poorly to approximately $4 \AA$ resolution irrespective of whether they were placed in a capillary or a cryo-loop and tested inhouse or at a synchrotron.

Consequently, further crystallization trials were carried out testing various additives and identified that $\mathrm{ZnCl}_{2}$ produced a second crystal form. To obtain these crystals, HPP epoxidase was incubated with $1 \mathrm{mM} \mathrm{ZnCl}$ for 30 min prior to setting up the drops and crystals were obtained under the same conditions as for form I. Hexagonal prisms, with a maximum size of $0.5 \times 0.25 \times 0.25 \mathrm{~mm}$ (Fig. $1 b$ ), grew in several days and are designated form II. 


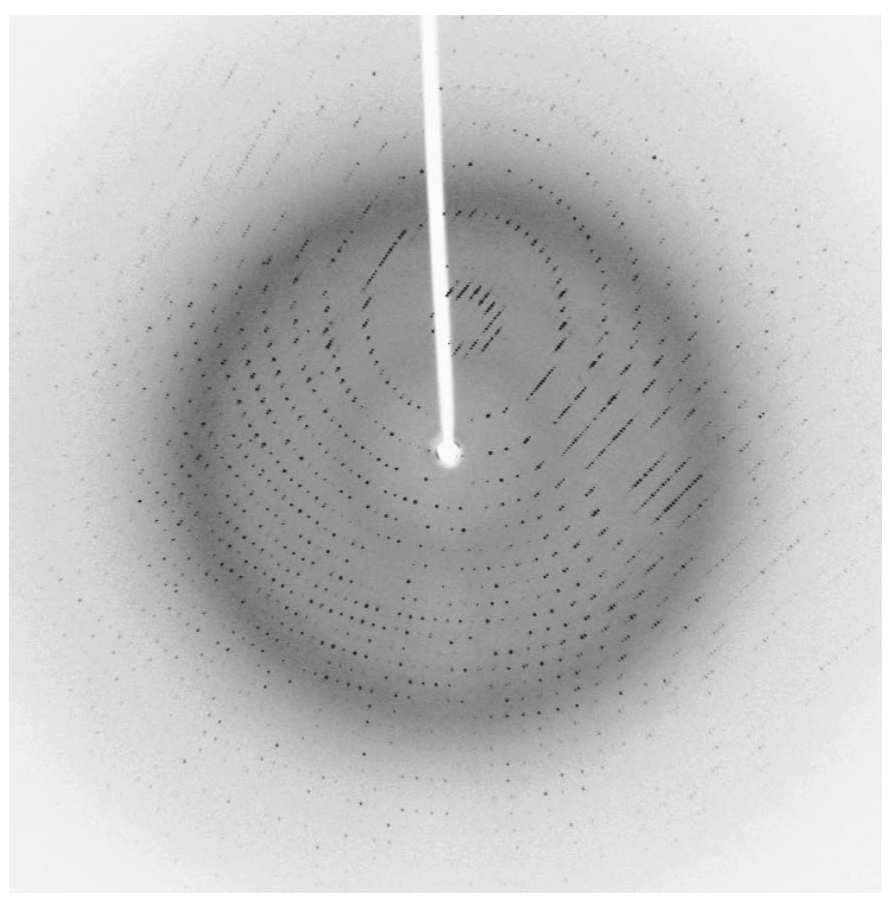

Figure 2

An example of diffraction obtained from the hexagonal crystal form II of HPP epoxidase. The crystal-to-detector distance is $200 \mathrm{~cm}$, the oscillation angle is $0.5^{\circ}$ and the exposure is $10 \mathrm{~min}$ with $\mathrm{X}$-rays produced at $40 \mathrm{kV}, 18 \mathrm{~mA}$.

\subsection{Cryoprotection and $\mathrm{X}$-ray diffraction}

Finding a cryoprotectant for HPP epoxidase crystals proved to be non-trivial. Initially, various organic solvents were tested as cryoprotectants by substituting $10-50 \%$ of the reservoir components with various organic solvents, e.g. glycerol, ethylene glycol, 2-methyl-2,4pentanediol etc. In all cases damage to the crystal was observed, which resulted in poor diffraction qualities and low resolution (typically $<4 \AA$ ). This was believed to be a consequence of the crystals being grown under such high salt [2.1 $\left.M\left(\mathrm{NH}_{4}\right)_{2} \mathrm{SO}_{4}\right]$ concentrations and therefore other compounds were tested such as sucrose, sodium formate, ammonium sulfate/phosphate, sodium chloride, sodium malonate and various oils. Attempts were also made to grow the crystals in solutions already containing cryoprotectants. Eventually, HPP epoxidase crystals were soaked in $3 \mathrm{MLi}_{2} \mathrm{SO}_{4}$ for up to 1 min without any signs of mechanical damage, before being flashcooled to $103 \mathrm{~K}$ in a stream of nitrogen gas. Crystals treated in this manner gave well ordered diffraction extending to high resolution and a low mosaic spread ( $\sim 4^{\circ}$; Fig. 2$)$.

Data were collected in-house on a Micromax 007 rotating-anode generator $(\mathrm{Cu}$-anode $\mathrm{X}$-ray source, $\lambda=1.5418 \AA$ ) with an R-AXIS
$\mathrm{IV}^{++}$dual image-plate detector system and processed with $D E N Z O /$ SCALEPACK (Otwinowski \& Minor, 1997) and the CCP4 suite of programs (Collaborative Computational Project, Number 4, 1994). The crystals displayed hexagonal Laue group 6/ $\mathrm{mmm}$ symmetry, with unit-cell parameters $a=86.44, c=221.56 \AA$. The data set is $99.6 \%$ complete to $1.9 \AA$ and 39459 unique reflections were obtained from 1099904 measurements. The data had an $R_{\text {merge }}$ of $7.6 \%$ overall and $33.7 \%$ in the highest resolution bin (1.97-1.90 $⿱$ ) and an overall $I / \sigma(I)$ of 28.0 with a value of 3.4 in the highest resolution bin. Inspection of potential systematic absences confirm a $P 6_{1 / 5}$ axis along $c$, suggesting that the space group is $P 6_{1} 22$ or the enantiomorph $P 6_{5} 22$. HPP epoxidase is a homotetramer in solution with a subunit of 198 amino acids and a molecular weight of approximately $21.4 \mathrm{kDa}$. A Matthews coefficient, $V_{\mathrm{M}}$ (Matthews, 1968), of $2.7 \AA \mathrm{Da}^{-1}$ correlates with a dimer of approximately $43 \mathrm{kDa}$ in the asymmetric unit with $55 \%$ solvent content.

These crystals are suitable for high-resolution crystallographic analysis and, since there is no obvious model for molecular replacement, work is under way to obtain experimental phases.

This work was funded by the BBSRC and the Wellcome Trust. We thank Frank Rao, Charlie Bond and Mike Hodkinson for advice and the European Synchrotron Radiation Facility for access.

\section{References}

Collaborative Computational Project, Number 4 (1994). Acta Cryst. D50, 760763.

El Zoeiby, A., Sanschagrin, F. \& Levesque, R. C. (2003). Mol. Microbiol. 47, 112.

Hendlin, D., Stapley, E. O., Jackson, M., Wallick, H., Miller, A. K., Wolf, F. J., Miller, T. W., Chaiet, L., Kahan, F. M., Foltz, E. L., Woodruff, H. B., Mata, J. M., Hernandez, S. \& Mochales, S. (1969). Science, 166, 122-123.

Kim, D. H., Lees, W. J., Kempsell, K. E., Lane, W. S., Duncan, K. \& Walsh, C. T. (1996). Biochemistry, 35, 4923-4928.

Liu, P., Liu, A., Yan, F., Wolfe, M. D., Lipscomb, J. D. \& Liu, H. W. (2003). Biochemistry, 42, 11577-11586.

Matthews, B. W. (1968). J. Mol. Biol. 33, 491-497.

Mirakhur, A., Gallagher, M. J., Ledson, M. J., Hart, C. A. \& Walshaw, M. J. (2003). J. Cyst. Fibros. 2, 19-24.

Otwinowski, Z. \& Minor, W. (1997). Methods Enzymol. 276, 307-326.

Patel, S. S., Balfour, J. A. \& Bryson, H. M. (1997). Drugs, 53, 637-656.

Schuck, P. (2000). Biophys. J. 78, 1606-1619.

Seto, H. \& Kuzuyama, T. (1999). Nat. Prod. Rep. 16, 589-596.

Shoji, J., Kato, T., Hinoo, H., Hattori, T., Hirooka, K., Matsumoto, K., Tanimoto, T. \& Kondo, E. (1986). J. Antibiot. (Tokyo), 39, 1011-1012.

Wilson, K. (1994). Current Protocols in Molecular Biology, edited by F. M. Ausubel, pp. 2.4.1-2.4.2. New York: Greene Publishing Associates.

Woschek, A., Wuggenig, F., Peti, W. \& Hammerschmidt, F. (2002). ChemBioChem, 3, 829-835.

Zhao, Z., Liu, P., Murakami, K., Kuzuyama, T., Seto, H. \& Liu, H. W. (2002). Angew. Chem. Int. Ed. Engl. 41, 4529-4532. 